\title{
ARTIGO \\ Hegel, Carl Schmitt e a mediação recíproca do social e do político ${ }^{1}$
}

\author{
Raphael Machado de Castro $^{2}$ | Vinícius Guimarães Dias Francisco ${ }^{3}$
}

Como citar este artigo: CASTRO, Raphael Machado de; FRANCISCO, Vinícius Guimarães Dias. Hegel, Carl Schmitt e a mediação recíproca do social e do político. Revista de Ciências do Estado. Belo Horizonte: v. 5, n. 2, e25196. ISSN: 2525-8036.

Resumo: O presente texto foi elaborado com o objetivo de aprofundar os estudos relativos à obra Hegel, Carl Schmitt: O Político entre a especulação e a positividade, de Jean-François Kervégan. Nesse trabalho, pretende-se estudar a temática relativa ao quarto capítulo da segunda parte do livro em questão, que trata, mais especificamente, sobre aspectos como a ética e a política, além da possibilidade de uma mediação recíproca entre Estado e sociedade civil.

Palavras-chave: Hegel; Político; Social; Carl Schmitt.

Recebido em 06.09.2020

Aprovado em 09.12.2020

Publicado em 23.12.2020

\section{INTRODUÇÃO}

O presente texto foi elaborado com o objetivo de aprofundar os estudos relativos à obra Hegel, Carl Schmitt: O Político entre a especulação e a positividade, de Jean-François Kervégan. Aprofunda-se a temática relativa ao quarto capítulo da segunda parte do livro em questão, que trata, mais especificamente, sobre aspectos como a ética e a política, além da possibilidade de uma mediação recíproca entre Estado e sociedade civil.

\footnotetext{
${ }^{1}$ Texto apresentado aos Seminários Hegelianos XXIV, coordenados pelos professores doutores Joaquim Carlos Salgado, José Luiz Borges Horta, Ricardo Henrique Carvalho Salgado e Paulo Roberto Cardoso.

${ }^{2}$ Graduando em Direito da UFMG, pesquisador voluntário em sede de Iniciação Científica no projeto Ciências do Estado: Caminhos e Soluções Institucionais para o Brasil, sob orientação do Prof. Dr. José Luiz Borges Horta

${ }^{3}$ Graduando em Artes Visuais pela Universidade Federal de Minas Gerais, com formação complementar em Filosofia e graduando em Arquitetura e Urbanismo pela PUC Minas.
} 
Em sua tese de cátedra da Universidade Federal de Minas Gerais, o jusfilósofo mineiro Joaquim Carlos Salgado indaga: Por que Hegel? Sua resposta retrata a importância do filósofo para o pensamento do ocidente:

\begin{abstract}
"Porque em Hegel terminam os esforços da cultura ocidental para pensar a totalidade num sistema de saber. E o momento de maturidade do período histórico que permitiu esse pensar sistemático é a chave de compreensão do mundo contemporâneo.” (SALGADO, 1996, p. 25)
\end{abstract}

Em princípio, é preciso compreender algumas das ideias tratadas nos últimos capítulos. Anteriormente, Kervégan buscou demonstrar no pensamento de Carl Schmitt a estruturação de uma oposição entre a ordem política e a desordem social, relacionando ambas ao plano da sociedade civil em Hegel e ao estado de natureza de Hobbes. Sobre esse aspecto no pensamento de Schmitt, temos que:

"Na sua concepção, o Estado e fundado no princípio da igualdade, portanto, o
Estado democrático, pois, para ele, se trata da igualdade dos cidadãos, portanto, um
Estado da liberdade, porque cidadão e aquele que e livre. E o cidadão e livre na
medida em que exerce a liberdade como autonomia política, autonomia política de
sua vontade, evidentemente, pela participação na lei que o rege." (SALGADO,
2006).

Para o autor francês, porém, essa oposição culminaria no revelar de uma incapacidade do decisionismo schimittino em preencher o seu próprio programa teórico, ao passo que, dentro do sistema hegeliano, tal interpretação se colocaria como contestável. Em suas palavras,

\footnotetext{
"Convém, no entanto, ir além: é o próprio pressuposto da interpretação schmittiana (...) que deve ser desmontado: Estado e sociedade, na perspectiva de Hegel, não são realidades heterogêneas (...). Mesmo se a verdadeira relação entre o Estado e a sociedade civil não se manifestou na realidade empírica, a não ser recentemente, ela não é menos exigida pelo seu respectivo conceito. É por isso que a interpretação desta relação (...) se revela incompatível com os princípios da filosofia política de Hegel e com sua filosofia do espírito em geral.” (KERVÉGAN, 2006, p. 236)
}

É a partir dessas constatações que Kervégan avança com suas reflexões acerca do social e do político tanto em Hegel quanto em Carl Schmitt, colocando principal foco, a partir daqui, no primeiro. Cabe colocar que tais ponderações vão de encontro às pesquisas dos professores brasileiros Francisco Pereira de Sousa, Marcos Lutz Müller e José Luiz Borges Horta, a respeito da representação política no Estado. E que há, decerto, um debate sobre os aspectos que envolvem a representação na Sociedade Civil e no Estado, bem como a respeito da relação deste último para com a fenomenologia do Espírito Absoluto. 
Müller, por exemplo, fixa o pensamento abstrato da Aufklärung, na Fenomenologia do Espírito, como ponto de origem da autoconsciência da liberdade absoluta, que para ele é crítica hegeliana a toda representação política. O professor recorre à Enciclopédia das Ciências Filosóficas para expor a respeito da suspensão do trabalho do negativo e do positivo na resolução da contradição inerente à liberdade absoluta. Porém, por outro lado, a reconstrução especulativa de Hegel de sua crítica ao terror jacobino pode ser interpretada, no referido trecho da Fenomenologia, não como origem, mas como efetivo processo histórico em curso. Que, como culmina no conceito puro, é raiz e "galho" que conduz ao fruto do Absoluto.

Deve-se então passar à apreciação de leituras que se debruçam sobre a construção da unidade entre eticidade e liberdade no Estado, bem como destes no cumprimento institucional e para além dele.

\section{A UNIDADE DA ESFERA ÉTICO-POLÍTICA}

Inicialmente, Kervégan aborda aspectos imprescindíveis do sistema hegeliano para a compreensão da relação entre eticidade, sociedade e Estado. Aqui, ele ressalta a posição do Espírito dentro do pensamento de Hegel enquanto "movimento de reconciliação infinita." (KERVÉGAN, 2006, p. 237). Em um sentido mais geral, o Espírito (do alemão Geist) pode denotar todos os aspectos relativos à mente humana e seus produtos, que se diferenciam da Natureza e da Lógica.“(...) o Estado hegeliano e, simultaneamente, a condição de efetividade e de objetivação consciente da vida ética, e é por isso que 'é do interesse absoluto da razão que o Estado, esse todo ético, exista.” (KÉRVEGAN, 2006, p. 153)

Dentro dessa constatação, por sua vez, o autor caracteriza o Espírito Objetivo como aquele que se manifesta na História e nela alcança sua própria racionalidade dentro do Estado. É a partir daí que Kervégan salienta parte de sua crítica a Carl Schmitt:

\footnotetext{
"Assim, a unidade do espírito determina a compenetração da objetividade institucional e da subjetividade natural-imediata que realiza efetivamente a vida ética graças à interação do Estado, de um lado, e de outro lado, da sociedade civil e da família." (KERVÉGAN, 2006, p. 237)
}

Em outras palavras, Jean-François Kervégan interpreta que, para Hegel, “a vocação ética específica do Estado se realiza graças à sua interação - é melhor falar de uma mediação recíproca - com a esfera anárquica da sociedade civil (...).” (KERVÉGAN, 2006, p. 237). A esfera ética seria, nesses termos, uma unidade racionalmente objetivada do Espírito. Logo, a 
interpretação de Schmitt de que não há ética sem a existência do Estado estaria incompleta por faltar a referida mediação recíproca entre os três momentos do Espírito Objetivo.

É o que Francisco Pereira de Sousa trabalha na perspectiva da objetivação da liberdade no mundo ético:

\begin{abstract}
"A vontade, segundo Hegel, só se realiza pondo-se na existência como mundo ético. A liberdade, conceptualizada no primeiro capítulo, carece de realidade. Sua efetividade é proporcionada pelo saber, querer e atuar dos indivíduos, que têm numa existência ética a base de apoio e o fim para suas ações. A vontade, desse modo determinada, encontra-se consigo mesma no seu próprio meio espiritual (espírito objetivo), em vez de permanecer submetida ao império do externo e alheio, da necessidade natural. O ético52 é o meio propriamente humano, uma ordem tanto subjetiva quanto objetiva - conhecida e querida pelos indivíduos - , onde estes podem atuar e realizar-se. Para Hegel, é apenas enquanto existência ética que a liberdade da vontade se efetiva, porque aqui a vontade tem como conteúdo o universalmente manifesto (deveres éticos) por meio das "instituições e leis existentes" da comunidade." (SOUSA, 2019, p. 49)
\end{abstract}

\title{
3 A MEDIAÇÃO POLÍTICA NA SOCIEDADE CIVIL: JUSTIÇA E POLÍCIA
}

Acerca da mediação política na sociedade civil, Kervégan afirma:

\begin{abstract}
"Do próprio conceito de vida ética, enquanto totalidade objetiva-subjetiva, se origina a necessidade de mediações entre o Estado e a sociedade civil. O Estado hegeliano é a pressuposição histórica concreta, e por isso, o 'verdadeiro fundamento' da sociedade civil, mas essa, em virtude inclusive da cisão que representa da totalidade ética com a predominância da particularidade, é a mediação lógica que permite a racionalidade ética." (KERVÉGAN, 2006, p. 240)
\end{abstract}

Assim, o autor afirma que a diferenciação necessária parte do entendimento que estes não são "vetores da racionalidade ético-objetiva, a não ser pela presença viva do outro neles" (KERVÉGAN, 2006, p. 240) e de que há, a partir de seus conceitos, uma diferenciação hierárquica realizada em função de uma identidade relativa.

Examinando o que se explicita sobre sociedade civil em Hegel, distinta das intenções schmittianas de configurar a sociedade como um estado de natureza, evidencia-se o entendimento de que a sociedade civil é um momento abstrato e distinguível dentro da totalidade ética, racional somente enquanto totalidade política. Portanto, como pressuposição conceitual e como resultada do Estado hegeliano, afirma-se resultante um conceito de sociedade civil em que impera um princípio particular de conciliação mecânica e sobre o qual qualquer apreensão de teor empírico deve ser tomada sob a ótica da relação com o universal ético político. 


\begin{abstract}
"Não se pode olvidar, então, que a defesa do Estado significa, também, e sobretudo, a defesa ética de seu povo. Deve tal divisa ser levantada de maneira séria e cuidadosa por aqueles que se interessam pela manutenção do Estado, pois sem sua base ética nada lhe resta senão uma população fragmentada em indivíduos atomizados em seus interesses particulares, e assim o Estado não deixa apenas de ser ético, nem Estado de Direito, mas deixa de ser um Estado.” (CARDOSO, 2016, p. 137)
\end{abstract}

O autor emprega a denominação hegeliana Estado externo ${ }^{4}$ a partir do entendimento de que a mediação política na sociedade civil parte, em sua racionalização, da presença ativa do Estado enquanto princípio diferenciado em sua superioridade. Assim se exige, não por ser esta amplitude política na sociedade uma liberdade à ingerência, mas sim suscitada pelo próprio conceito de Estado e sua modulação com a sociedade civil. Logo, para Kervégan, fica sucumbida, a partir da subsunção do particular ao universal, à compreensão de que a ação do Estado opera sobre a sociedade civil e de que esta tarefa é incumbida ao poder governamental.

\begin{abstract}
"Carl Schmitt rejeita veementemente e tese de que a liberdade do indivíduo possa estabelecer um limite a atuação do Estado. No liberalismo, a Economia assume o monopólio das decisões políticas e isso significa a destituição do Estado como instituição política suprema. Contra a concepção liberal de política, Schmitt vai Propor a noção de 'Estado total', para anunciar o advento de uma nova ordem política que deve redimir o Estado e pôr fim a era das neutralizações, submetendo novamente a Economia aos imperativos da política." (ARRUDA, 2003, p. 56-86).
\end{abstract}

A empreitada em questão é encargo primeiramente da justiça, referida em Hegel como dever e direito do poder público. Como administração concreta do direito abstrato, a sua gerência é uma forma do universal que garante a estabilidade a partir da sanção de sua supremacia sobre os objetivos particulares. Estabelece-se assim a assertiva de que o funcionamento da sociedade civil, enquanto circunscrita no ditame de uma ordem social espontânea, supõe o amplo efeito de uma ordem jurídica concreta, um nomos.

“A ideia de justiça no mundo contemporâneo é, pois, entendida como a processualidade histórica da inteligibilidade do direito, o resultado dessa

\footnotetext{
4 "Do "Direito Estatal Interno " da Constituição, Hegel passa para o "Direito Estatal Externo" (\$330-340). Que ele não fala de direito internacional, é algo que se explica a partir de sua própria exposição. Ao contrário dos tratados celebrados no interior de um Estado, os celebrados entre Estados distintos desconhecem qualquer instância que garanta o seu cumprimento (...). Hegel oferece aqui uma descrição desencantada e desencantadora da situação entre os estados do mundo, cuja exatidão apenas se confirmou, e ainda confirma, com o tempo que se seguiu. "Del «Derecho estatal interno», de la Constitucíon, Hegel passa al «Derecho estatal externo» (\$330-340). Que no hable de Derecho internacional, es algo que se explica a partir de su propria exposicíon. A diferencia de los tratados concluídos dentro de um Estado, los realizados entre Estados diferentes no conocen ninguna instancia que garantisse su cumplimiento (...). Hegel ofrece aqui una desencantada, y desencantadora, descripción de la situacíon entre los Estados del mundo, cuya corrección no hizo más que confirmarse, y aún confirma, con el tiempo que siguió.” (JAESCHKE, 1998, p. 33)
} 
processualidade que se acumula no presente histórico do nosso tempo, e se expressa na efetividade do direito na ordem social justa como sentido universal, vale dizer, que efetiva a legitimidade do poder mediante a procedimentalidade democrática, enquanto esse poder tem origem na vontade popular e se estrutura na divisão da competência para o exercício do poder, com vistas ao seu núcleo (a declaração de direitos) e conteúdo axiológico, como processo historicamente revelado, constituído dos valores fundamentais da cultura, então formalizados conscientemente na declaração dos direitos fundamentais, na constituição, para a sua plena efetivação." (SALGADO, 2007, p. 257)

A livre interação das particularidades não depende, em Hegel, de uma mão invisível, de cunho liberalista. Depende também da conveniente efetuação do bem-estar como dever e direito por parte da polícia. Termo que aqui excede a noção comum de uma instituição estatal de manutenção da ordem pública, aplicando-se também como uma polícia econômica e a da ação social, de caráter social e não exclusivamente estatal. Para Kervégan, esses exemplos demonstram essencialmente que a interpretação de Schmitt da relação antagônica entre Estado e sociedade é equívoca. Além disso, para pensador francês, os próprios estudos de Schmitt demonstram a não obstância do pensamento hegeliano em se limitar a uma organização prática da esfera econômica. Por outro lado,

\footnotetext{
"Quando a organização política perde a natureza pela qual é o fim supremo a que se subordinam todas as particularidades e interesses individuais ou quando o Estado de fim passa ser meio para as satisfações desses interesses, nas suas relações empíricas, então não há mais Estado. Daí a amarga advertência de Hegel em Die Veriassung Deutschlands: "ist kein Staat mehr" (A Alemanha não e mais um Estado). Não e mais um Estado a organização assim chamada (se se pode chamar organização) em que o interesse particular ou os privilégios se consagram ou predominam sobre o interesse comum e sobre os direitos de igualdade inscritos no racional fundamento da humanidade. Nem o universal sem o interesse particular", sem os indivíduos na sua vontade autônoma, nem o particular (os indivíduos como pessoas isoladas em seus fins imediatos) sem o universal que se caracteriza na sua essência ética (as leis, instituições e poder) podem, isoladamente, constituir um Estado; seria pura abstração." (SALGADO, 1996, p. 412)
}

Bem como se entende, a partir dessas explanações, que são comuns nessa estrutura a evocação necessária do Estado ante a sociedade civil em seus aspectos contraditórios e da caracterização abstrata em seu entendimento; e a necessidade inconsciente de ações particulares dentro da liberdade, sobretudo do campo econômico, cujos interesses particulares, no entanto, dependem de uma intervenção superior. Segundo o próprio Hegel:

"Esse interesse invoca a liberdade contra uma regulamentação superior, mas, quanto mais se afunda no fim egoísta, tanto mais requer uma tal regulamentação para ser reconduzido ao universal, para atenuar e abreviar as convulsões perigosas e a duração do intervalo, no qual as colisões devem ser liquidadas pela via de uma necessidade inconsciente." (HEGEL, 2010, p. 220) 
Assim, Kervégan afirma tais exemplos como demonstrações de que o modelo hegeliano de interação entre tais partes procede como um princípio racional dentro da ordem social em relativa autonomia. O que não corresponde à visão liberal de o intervencionismo ser uma "interferência indevida de uma ordem espontânea" (KERVÉGAN, 2006, p. 246), nem a sugestão schmittiana da anulação de uma suposta incerta ordem por um terceiro superior.

\section{O CUMPRIMENTO INSTITUCIONAL DO SOCIAL E OS ESTADOS MODERNOS}

No entendimento de Jean-François Kervégan, a cisão da problemática hegeliana em relação aos argumentos liberalistas é definitiva quando Hegel estabelece que a mediação estatal - a qual integra sobre a diferenciação social - é acompanhada e provida através de um cumprimento institucional.

Considerando que a sociedade civil está condicionada logicamente à prefiguração necessária do Estado racional; e que não corresponde a uma sociedade de mercado, pois se supõe como princípio próprio a esta uma mediação política a partir da universalidade formal do Estado, é possível respaldar aqui a institucionalização da vida social, que permite a qualificação ética do estrato distintivo e modulado da sociedade civil em relação ao Estado. E permite à própria instituição uma articulação equilibrada entre autoridade e liberdade.

\footnotetext{
"A história do pensamento ocidental é um embate entre a liberdade e o poder. Trata -se de um movimento dialético da mesma realidade ética, a política e o direito, ou da liberdade na sua face subjetiva e da liberdade no seu aspecto objetivo, que aparecem numa unidade imediata no Estado grego. Com a dissolução do Estado ético grego, que representa no aspecto político a unidade desses dois elementos no momento da imediatidade, ocorre uma cisão, que só no Estado Democrático contemporâneo se supera. É no Estado de Direito Democrático contemporâneo que surge a idéia de autonomia (Kant) privada e pública (participação na elaboração das leis que regem a própria conduta), na experiência da Revolução, com o que se põe em definitivo a unidade do poder e da liberdade." (SALGADO, 1983, p. 3).
}

A realização das disposições éticas especificadas pela mediação política da ordem momentânea do sistema de necessidades demanda a existência de tais instituições próprias à sociedade civil, corporações em que residem a consciente noção do retorno ético imanente à realização da sociedade civil. E com a qual cooperam a regulação inconsciente - dos mecanismos de mercado - e a mediação, segundo Kervégan externa, realizada pela justiça e pela polícia.

Além disso, na qualidade de expressão jurídica de um interesse organizado se reconhece uma integridade sob a figuração de uma honra profissional e da qualificação legal. 
Em que o membro da sociedade civil não será somente átomo do sistema, exercerá dentro da jurisdição competida uma função edificadora e política, incumbido de garantir respeito, direitos e deveres à instituição dentro da noção de direito abstrato.

Para Kervégan, tal vocação da corporação a torna a "segunda raiz ética do Estado" (KERVÉGAN, 2006, p. 263), sendo a primeira a família. Tanto por ser prefiguração da instituição política ao confluir o interesse social à universalidade da forma jurídica, notadamente um meio termo entre singularidade e universalidade. Quanto é o local em que surge, na particularidade, uma subjetividade constante de uma disposição ética e política ordenada pelo universal, o que deve, segundo o autor francês, legar à corporação uma perspectiva liberal de autonomia social e política. Já que carregar-se da noção de pertencimento à universalidade e encarregar-se de sua corporação leva os indivíduos a superar seus egoísmos e interesses privados, e nas condições de Hegel, à efetividade racional do político.

\begin{abstract}
"Estado e a substância ética consciente-de-si, a união dos princípios da família e da sociedade civil; a mesma unidade que na família está como sentimento do amor é sua essência; mas que, ao mesmo tempo, mediante o segundo princípio, do querer que-sabe e por si mesmo atua, recebe a forma de universalidade [que é] sabida; esta, como suas determinações que se desenvolvem no saber, tem, para o conteúdo e fim absoluto, a subjetividade que-sabe, isto é, quer para si mesma esse racional. (...) $\mathrm{O}$ Estado tem o dado, enfim, de ser a efetividade imediata de um povo singular e naturalmente determinado. Enquanto indivíduo singular, ele é exclusivo em relação aos outros indivíduos da mesma espécie. No seu relacionamento, de uns com os outros, tem lugar o arbitrário e a contingência, porque o universal do direito, em razão da totalidade autônoma dessas pessoas, somente deve ser entre elas, não é efetivo. Essa independência faz do conflito entre elas uma relação de violência, um estado de guerra, para o qual a situação universal se determina em vista do fim particular da conservação da autonomia do Estado perante os outros, em um estado de bravura." (HEGEL, 1995, p. 306-324)
\end{abstract}

Assim, com o cumprimento institucional através da modulação dialética da corporação em sua justificativa legal relativa ao Estado, é possível chegar para o referido autor à sociedade civil como condição dialética de uma totalidade política segundo a ordem da liberdade racional. No seguinte subtítulo do Capítulo, 'Uma instituição moderna? ', o francês reconsidera a razão acima à qual chega acrescendo a ela um argumento de cunho empírico e histórico. Para ele, Hegel tem consciência da ameaça de "esclerose" econômica e social que podem conviver com as instituições corporativas. Historicamente, o espírito corporativista (Zunftgeist) comprometeu o desenvolvimento econômico e político das nações europeias.

"Uma das características da sociedade civil é ser ela um sistema das necessidades e, como tal, não realizar no indivíduo a sua liberdade, ou seja, o que ele é em si, 
pessoa. Como pessoa, o homem é ser-para-si, portanto livre, na medida em que é autônomo e sabe dessa liberdade. Essa substância espiritual do homem, esse logos theoretikós-praktikós, digamos, só é possível realizar-se na sua plenitude na vida social, e essa só pode existir enquanto sociedade livre num sistema de normas, autodeterminações que o homem cria para tornar possível essa sociedade, de indivíduos como pessoas. Não é necessário, portanto, provar a liberdade numa primeira instância (embora o faça Hegel). É suficiente tê-la como postulado transcendental, a priori (Kant), mas que explica a realidade do mundo normativo. A esfera da pessoa, portanto, realiza-se na organização política da sociedade, segundo a tradição que vai de Aristóteles, através de Hegel, até nossos dias. Mesmo a idéia de uma revolução socialista como abolição do Estado outra coisa não preconizou, implicitamente, senão tentar repatriar a idéia aristotélica de Estado.” (SALGADO, 1983, p. 6).

Tal debate tem espaço em diversos textos de Hegel, nos quais se desenvolve um discurso apoiado em conhecimentos históricos e precisos sobre políticos e que esclarecem a doutrina das corporações tal qual descrita na Filosofia do Direito. ${ }^{5}$ Demonstram uma rejeição do filósofo à estrutura corporativa que acompanha a rigidez estrutural do Antigo Regime, a qual concentra as severas críticas. Essas apontam para um sistema obsoleto, nocivo e enrijecedor nos planos político e econômico devido à impotência estatal em garantir o crescimento da economia e de diversificar e controlar os investimentos, que passam a uma paralela multiplicação de "círculos particulares" que tendem a desenvolver particularidades as quais, como aproxima Schmitt, por sua vez se inclinam a plurais interesses organizados, explicitando uma privatização do direito público pelo crescimento das capitulações destas comunidades territoriais ou profissionais. Pois com o tempo dotam-se de direitos e privilégios

\footnotetext{
5 "A atualidade da análise de Hegel sobre a sociedade civil como sistema das necessidades, não ético, embora não antiético, mostra, com clareza, a nova forma desse sistema: em vez de progredir para a superação das conexões de mercado que determinam a vida das pessoas, a sociedade civil faz do Estado o instrumento da despersonalização, da perda da substância espiritual da liberdade. Com efeito, não é simplesmente a valoração do homem pelo que ele faz, indiferente do saber consciente desse fazer, o que em si mesmo não compromete a sua liberdade, mas a sua instrumentalização enquanto é reduzido à pura dependência como ser-para-um-outro, com total supressão do seu ser-para-si livre, ou fim em si mesmo. Na sociedade civil contemporânea, o homem passa a ser instrumento para algo e, na medida em que é instrumento para algo, coisa, é instrumento para o outro, pessoa, que o domina, segundo a estrutura da relação senhor-escravo, guardada evidentemente a essencial diferença entre a relação de servidão ou escravidão e a do trabalho livre. O que se quer dizer é que a sociedade civil criou um grupo que domina a técnica através do econômico, ou seja, transformou em mercadoria a força de trabalho e, como qualquer outro valor quantitativo, não vê no trabalhador senão a força do trabalho e sua capacidade de fazer, impondo-lhe o regime da oferta e da procura, expulsando-o da estrutura essencial da unidade de produção, a empresa. $\mathrm{O}$ trabalhador é descartado quando não necessário ou quando diminui o lucro; a empresa é do capitalista, não da unidade dialética do trabalho e do capital. A palavra mágica com que se opera essa transformação é o econômico. Mágica porque o econômico é apenas uma ficção, pois o real é a técnica de produzir coisas na natureza, que depois são transformadas em mercadorias pela magia do econômico. $\mathrm{O}$ econômico, porém, é também uma técnica, mas tautológica: produção do que está produzido pelo trabalho (da natureza transformada pelo fazer). O fazer econômico, o produzir o econômico, esta é a determinante da sociedade civil. E os que dominam esse fazer econômico, que não são as ides trabalhadoras, não se limitam ao controle da economia na sociedade civil; precisam de um instrumento poderoso; não mais para servir de porrete contra os trabalhadores, como pensou Marx, mas como instrumento de produção das regras do jogo das relações sociais, especificamente da economia, com subordinação de todas as demais relações. Precisa da organização política." (SALGADO, 1983, p. 6).
} 
consideráveis, submetendo a si a condição de aceitação por parte do poder superior. "A teoria do liberalismo obstaculiza o Estado para a proteção individual e da propriedade privada [...] subordinando o político ao econômico". (SCHMITT, 1992, p. 88-97)

Aqui, o paralelo com o pensamento do filósofo Joaquim Carlos Salgado sobre certos aspectos do tempo presente e o desenrolar do caminho do Estado na História fica evidente:

\begin{abstract}
"No Estado poiético, o produto do fazer é o econômico, que nenhum compromisso tem com o ético, e procura, com a aparência de cientificidade, subjugar o político, o jurídico e o social. Não é ético, porque o seu fazer não se dirige a realizar os direitos sociais. Evidentemente, se o Estado realiza os direitos sociais, esse fazer é ético.

Cria-se, então, no Estado, um corpo burotecnocrata que passa a exercer a soberania, com total sujeição do político e do jurídico em nome do corpus econômico da sociedade civil. Não se nega que o técnico ou o cientista econômico sejam essenciais no Estado contemporâneo. Não, porém, o tecno-crata, detentor do poder de decisão política, que no Estado democrático não lhe pertence. Com o aparecimento desse aparelho, abre-se uma cisão no Estado: de um lado, a organização ética da sociedade em que as decisões de soberania se dirigem ao bem comum ou à realização de uma ordem social justa e, de outro, a burotecnocracia malabarista, que impõe o fazer do produto econômico sobre o interesse social e jurídico, procurando mostrá-lo, através de sua cartola e de sua hábil prestidigitação, como interesse público absolutamente sobrevalente.

A cisão do Estado está, pois, nesse embate que se trava dentro dele mesmo, criando dois estados: o estado poiético do domínio burotecnocrata e o estado ético do domínio da sociedade política, enquanto Estado Democrático de Direito. É fácil verificar isso no fortalecimento do aparelho burocrático denominado Banco Central, em todo o Ocidente, das bolsas de valores e da massificação globalizada do consumo das mercadorias, mas com a concentração da produção de tecnologia de ponta e do controle do capital financeiro." (SALGADO, 1983, p. 6).
\end{abstract}

O texto de Kervégan, por sua vez, retorna à Hegel e volta-se a outra comparação a fim de comentar sobre essa subordinação tida no texto como nefasta. Pode parecer antiquado na modernidade e altamente paradoxal, visto que a constituição alemã - a Ständestaat, cujo apoio paradoxal persistiu da parte de Hegel - não possuía em si as condições de ambientar um Estado forte que desse amparo a essas instituições, e, no entanto, Hegel mantém tal postura por entender a institucionalização como necessária, e tal concepção estava mantida, ainda que como mera sobrevivente, na carta alemã.

Exime-se uma contraprova concedida pela Inglaterra e pelos mecanismos de sua sociedade de mercado amparados nas obras dos economistas ingleses. Kervégan avalia que a Filosofia do Direito demonstra como a estratégia inglesa é arriscada por possivelmente comprometer a dimensão ética a ser comportada pela sociedade civil. O endurecimento das críticas ao liberalismo aqui acompanha as consequências negativas do liberalismo inglês. Segundo Hegel, "Na Inglaterra, reinam a pobreza e a proletarização mais monstruosa, e 
grande parte deste câncer deve ser atribuído à supressão das corporações." (HEGEL, 2010, p. 271)

A elucidação da necessidade de tal mediação fez-se necessária quanto à filosofia política hegeliana. E, segundo o acadêmico francês, demonstram que a posição de Schmitt é cofluente do desempenho de tal pensamento, mostrando que as opções deste são resultantes de uma torção sistemática, coerente (somente segundo suas intenções) com as proposições que busca e se sustentando em Hegel.

No entanto, retorna aqui o ponto central da problemática schmittiana, que se trata da recusa do tipo de racionalidade dialética trabalhada por Hegel e, portanto, de suas derivações sobre a filosofia política. E o que confere à sua teoria a possibilidade da superação da rigidez e a eficiência em tratar a complexidade do Estado Moderno, relegando a tentativa de Schmitt uma rigidez conceitual e certamente diferencia os caminhos adotados. A separação definitiva destes, como indica o fim do capítulo, virá da problemática da representação, ponto em que desde já se distinguem radicalmente.

\section{ESTADOS SOCIAIS E A MEDIAÇÃO SOCIAL DO POLÍTICO NA FILOSOFIA DO DIREITO}

Entende-se, desse modo, que a justiça e a polícia são as formas de mediação política do espaço social e que as representações políticas da sociedade civil estabelecem a mediação social do político. Assim, a subordinação da sociedade civil em relação ao Estado proposta por Schmitt é considerada por ele unilateral e sem os fatores de reciprocidade anteriormente elencados.

Kervégan avança, a partir desse ponto, para uma reflexão a respeito da distinção explícita proposta por Hegel entre Estado e sociedade civil. O autor caracteriza essa diferenciação como "inovação da obra de maturidade" (KERVÉGAN, 2006, p. 247) do filósofo alemão e elenca como principal causa a essa mudança a "ruptura com o modelo grego da vida ética e a crítica do curso político da Revolução Francesa” (KERVÉGAN, 2006, p. 247), além de "uma redefinição do estatuto dos estados sociais" (KERVÉGAN, 2006, p. 247).

A respeito da última constatação, Kervégan descreve, no pensamento de Hegel, uma apreensão ética e política acerca dos Estados Sociais, demonstrada a partir da análise de que 
transformar a 'relação de dependência física' em uma 'dependência viva'." (KERVÉGAN, 2006, p. 247)

Tem-se, então, a partir dessa mudança, um endurecimento da visão de Hegel acerca da diferenciação entre o universal e o particular, visto que o segundo, colocado como o burguês, passa a se preocupar somente com seu trabalho, sua família e suas relações jurídicas contratuais. Para Kervégan, é nessa alteração que reside "o reconhecimento da mediação social do político" que, em sua visão, ocupa lugar essencial na Filosofia do Direito hegeliana. Em suas palavras,

\begin{abstract}
"A sociedade civil é, num plano geral, a raiz ética do Estado; mas a cultura social particular, a ética profissional ou ainda o 'espírito da corporação' são as raízes de uma cultura política verdadeira, pois acarretam uma adesão da subjetividade ao universal em e pela preocupação que ela tem por seus interesses particulares. Nada revela melhor a mediação (própria ao mundo moderno) do político pelo social que essa articulação objetiva e, ao mesmo tempo, subjetiva do particular e do universal (...)." (KERVÉGAN, 2006, p. 261)
\end{abstract}

\title{
6 DISCUSSÕES E CONSIDERAÇÕES FINAIS
}

Durante todo o capítulo estudado, viu-se um esforço por parte de Kervégan em demonstrar que o entendimento de Carl Schmitt acerca da relação entre a sociedade civil e o Estado é fruto de uma concepção unilateral da influência de ambas as categorias no que diz respeito à política e a ética. Para o autor, tornou-se visível que, tomando como base o sistema hegeliano, haveria a necessidade de um aprofundamento no tratamento dado aos momentos do Espírito Objetivo, visto que a relação entre esses se mostraria como mais complexa do que a mera dualidade na qual a sociedade civil estaria hierarquicamente subordinada ao Estado.

\footnotetext{
"Observa-se que o Estado surge quando uma aglomeração social passa a se identificar eticamente como povo, e ele se efetiva a partir das categorias hegelianas do Espírito Objetivo, em um movimento dialético que suprassume o momento particular anterior da sociedade civil, como uma aglomeração de interesses disparatados que não abarcam uma essência ética. Quem coloca os direitos fundamentais não se mostra suficiente para manter um Estado no seu conceito." (CARDOSO, 2016, p. 162)
}

Para Kervégan, os aspectos da teoria schmittiana como seu "antiliberalismo político, a antropologia pessimista e seu fundo teológico e o decisionismo político" (KERVÉGAN, 2006, p. 261) estariam elencados a uma "recusa do tipo de racionalidade trabalhado pela filosofia de Hegel” (KERVÉGAN, 2006, p. 261), ao ponto que as relações propostas por Schmitt no que tange a sociedade civil e o Estado encontram seus limites de assimilação no sistema hegeliano. 


\begin{abstract}
"Segundo alerta Carl Schmitt, o liberalismo apresenta-se como uma negação do político, e resulta de 'uma tentativa de neutralizar e despolitizar a existência política'. Segundo ele, o liberalismo não tem por finalidade ideológica extinguir o aparato estatal, até porque isso seria um grande contrassenso, visto que é o Estado, em um primeiro aspecto, que, por intermédio do Direito, defende a propriedade, a ordem econômica, estatui a segurança e a certeza jurídica. E exatamente por isso, inclusive, que Hegel localiza a função jurisdicional na sociedade civil, e não no Estado. Mas essa sociedade civil, diz Schmitt, não se contenta em ser reconhecida e tutelada pelo Estado, e, para além de pretender se alargar e se libertar de seu campo de intervenção, pretende atrelá-lo a seus interesses, sujeitando-o a seus imperativos." (CARDOSO, 2016, p. 123)
\end{abstract}

Porém, cabe aqui ressaltar que a chave para a compreensão do caminhar do Espírito Objetivo hegeliano talvez não esteja na assimilação de uma mediação recíproca entre os momentos referidos (família, sociedade civil e Estado), como afirma Kervégan. É possível relacionar a complexidade do caminhar histórico ${ }^{6}$ com o entendimento de que "O Estado é o fim último do indivíduo e o indivíduo fim último do Estado. "7 (SALGADO, 1996, p. 421). Ainda nas palavras de Joaquim Carlos Salgado,

\begin{abstract}
"Hegel, com efeito, distingue diversamente da teoria tradicional, o aspecto econômico da sociedade civil do aspecto político e ético do Estado (em sentido estrito). Entretanto, essa distinção não é abstrata; a sociedade civil é momento do Estado; não é algo que se superpõe o Estado. Assim, o Estado contém a sociedade civil (...)." (SALGADO, 1996, p. 421)
\end{abstract}

Logo, a sociedade civil e a família estariam suprassumidas no Estado hegeliano, ou seja, a necessidade de se aprofundar as relações trabalhadas por Carl Schmitt nesses aspectos não viria da existência uma mediação recíproca entre categorias anteriormente ditas acerca do ético e do político $^{8}$. Por outro lado, se valeria da compreensão que os momentos pretéritos ao Estado se encontrariam nele próprio como dialeticamente conservados e elevados a um plano superior. Nas próprias palavras de Hegel,

\begin{abstract}
"Se o Estado é confundido com a sociedade civil-burguesa, e se sua determinação é posta na segurança e na proteção da propriedade e da liberdade pessoal, então o interesse dos singulares enquanto tais é o fim último, em vista do qual eles estão unidos, e disso se segue, igualmente, que é algo do bel-prazer ser membro do Estado. - Mas ele tem uma relação inteiramente outra com o indivíduo; visto que ele é o espírito objetivo, assim o indivíduo mesmo tem apenas objetividade enquanto é um membro dele. A união enquanto tal é, ela mesma, o conteúdo verdadeiro e o fim, e a determinação dos indivíduos é levar uma vida universal; (...).” (HEGEL, 2010, p. 230)
\end{abstract}

\footnotetext{
6 "Em Hegel, o Estado é ideia, mas ideia manifesta na História. O tema central da filosofia hegeliana é a História, tomada como espaço privilegiado de manifestação do Espírito, do Absoluto.” (HORTA, 201, p. 27)

${ }^{7}$ SALGADO, Joaquim Carlos. A ideia de justiça em Hegel. São Paulo: Edições Loyola, 1996, p. 421.

${ }^{8}$ Nesse caso, a sociedade civil não seria a raíz ética do Estado como afirma Kervegán, mas "o ponto de chegada é o direito, no qual necessariamente está assumida a pessoa moral, aqui entendido, portanto, como o maximum ethicum." (SALGADO, 2007, p. 267)
} 


\section{REFERÊNCIAS BIBLIOGRÁFICAS}

ARRUDA, Jose Maria. Carl SCHMITT: politica, Estado e direito. In: OLIVEIRA, Manfredo; AGUIAR, Odilon Alves; SAHD, Luiz Felipe Neto de Andrade e Silva (Org.). Filosofia política contemporânea. Petrópolis: Vozes, 2003.

CARDOSO, Paulo Roberto. Dietética Cultural: Estado, soberania e defesa cultural. Belo Horizonte: Universidade Federal de Minas Gerais, 2016. (Tese, Doutorado em Direito).

HEGEL, Georg.Wilhelm.Friedrich. Enciclopédia das Ciências Filosóficas em Compêndio. São Paulo: Loyola, 1995.

HEGEL, Georg Wilhelm Friedrich. Filosofia do Direito. São Leopoldo, RS: UNISINOS, 2010.

HORTA, José Luiz Borges. História do Estado de Direito. São Paulo: Alameda, 2011.

JAESCHKE, Walter. Hegel. La conciencia de la modernidade. Madrid: Akal, 1998.
KERVÉGAN, Jean-François. Hegel, Carl Schmitt: o político entre a especulação e a positividade. Barueri: Manole, 2006.

SALGADO, Joaquim Carlos Salgado. I Congresso Mineiro de Filosofia do Direito [conferência]. Faculdade de Direito da UFMG: Belo Horizonte, ago. 2006.

SALGADO, Joaquim Carlos. A ideia de justiça em Hegel. São Paulo: Edições Loyola, 1996.

SALGADO, Joaquim Carlos. A ideia de justiça no mundo contemporâneo: fundamentação e aplicação do direito como maximum ético. Belo Horizonte: Del Rey, 2007.

SALGADO, Joaquim Carlos. O Estado Ético e o Estado Poiético. Revista do Tribunal de Contas do Estado de Minas Gerais, v.27. Belo Horizonte, TCE/MG, 1983.

SCHMITT, Carl. O Conceito do Político. Petrópolis: Vozes, 1992.

SOUSA, Francisco Pereira de. Hegel e a representação política. Goiânia: Philos, 2019.

\section{HEGEL, CARLL SCHMITT AND THE RECIPROCAL MEDIATION OF THE SOCIAL AND THE POLITICAL}

Raphael Machado de Castro | Vinícius Guimarães Dias Francisco

How to cite this article: CASTRO, Raphael Machado de; FRANCISCO, Vinícius Guimarães Dias. Hegel, Carl Schmitt e a mediação recíproca do social e do político. Revista de Ciências do Estado. Belo Horizonte: v. 5, n. 2, e25196. ISSN: 2525-8036.

Abstract: The following text was prepared in order to deepen the studies related to the work Hegel, Carl Schmitt: O Político entre a especulação e a positividade, by Jean-François Kervégan. In this text, we intend to study the theme related to the fourth chapter of the second part of the book in question, which deals more specifically with aspects such as ethics and 
politics, in addition to the possibility of a reciprocal mediation between the State and civil society.

Keywords: Hegel; Political; Social; Carl Schmitt. 